\title{
La nueva simbología en Venezuela a través de actos de jura, festividades y música a principios del siglo XIX
}

\author{
The new symbology in Venezuela through acts of swearing, festivities \\ and music in the early nineteenth century
}

\section{María de los Ángeles Castro Pirela*}

\section{RESUMEN}

En el contexto de símbolos, valores, actitudes y comportamientos de orden tradicional, la construcción de la república de Venezuela requiere legitimar una nueva simbología institucional y política. El presente trabajo analiza y busca generar nuevas aportaciones que ayuden a comprender en el nacimiento de la nueva identidad "republicana" durante las primeras décadas del siglo XIX. El objetivo es destacar los dispositivos discursivos que explican tal construcción a partir de algunas ceremonias, actos públicos, fiestas, canciones que ponen en escena símbolos y signos que aunque en el contexto de corte antiguo "legitimadores de la monarquía y sus prácticas," buscan durante toda la coyuntura independentista imponerse y hacerse necesarios con el propósito de asegurar los principios que consoliden efectivamente la estabilidad de la nueva república. Para el análisis de los alcance y límites de la nueva simbología republicana, ha sido fundamental la aplicación del método histórico, es decir, partiendo de unas problemáticas se procedió a la localización, arqueo y revisión de diversidad de fuentes, siendo las principales las del Archivo General de Indias, para comprobar la factibilidad y utilidad de las mismas en el abordaje de la investigación y lograr contrastar la información obtenida con el problema propuesto y así dar cuenta de la realidad objeto de estudio; dichas fuentes son un valioso aporte que permite no solo comprender sino articular el estudio con otras investigaciones relacionadas con las prácticas y comportamientos de las sociedades pertenecientes al régimen monárquico Español y que prácticas y dispositivos simbólicos son los que las nacientes repúblicas sobre todo en nuestra América Latina se apropian e incluyen como parte de esa realidad material y simbólica que explica la construcción de las repúblicas siendo nuestro caso el de Venezuela.

Palabras Clave: Simbología, antiguo régimen, república, ceremonias, fiestas.

\footnotetext{
${ }^{*}$ MgS. Historia de Venezuela por la Universidad del Zulia, profesora e investigadora en el departamento de ciencias sociales de la Universidad del Zulia. Maracaibo, Venezuela. Correo electrónico: marielos737@ hotmail.com
} 


\title{
RECIBIDO: Julio 2017 ACEPTADO: Octubre 2017
}

\begin{abstract}
In the context of symbols, values, attitudes and behaviors of a traditional order, the construction of the Republic of Venezuela requires legitimizing a new institutional and political symbology. The present work analyzes and seeks to generate new contributions that help to understand the birth of the new "republican" identity during the first decades of the 19th century. The objective is to highlight the discursive devices that explain such construction from certain ceremonies, public acts, parties, songs that put on stage symbols and signs that although in the context of the old court "legitimators of the monarchy and its practices," they look for all the independence situation must be imposed and made necessary in order to ensure the principles that effectively consolidate the stability of the new republic. For the analysis of the scope and limits of the new republican symbology, the application of the historical method has been fundamental, that is to say, starting from some problems, the location, arching and revision of the diversity of sources was proceeded, the main ones being those of the Archive General de Indias, to verify the feasibility and usefulness of the same in the approach of the investigation and to be able to contrast the information obtained with the proposed problem and thus give an account of the reality under study; These sources are a valuable contribution that allows us not only to understand but to articulate the study with other investigations related to the practices and behaviors of the societies belonging to the Spanish monarchical regime and that symbolic practices and devices are those that the nascent republics especially in our Latin America they appropriate and include as part of that material and symbolic reality that explains the construction of the republics, being our case that of Venezuela.
\end{abstract}

Keywords: Symbology, ancient regime, republic, ceremonies, parties.

\section{Introducción}

Es evidente que los signos y símbolos de poder visibilizan una intencionalidad política y develan el significado y alcance que en el caso venezolano, entre 1808 y 1830 tienen las nuevas ideas. Así, algunas manifestaciones alegóricasactos de jura, festividades, rituales, diversiones y espectáculos públicos-, que aunque en el contexto de referentes de corte antiguo, intentan de uno u otro modo expresar las nuevas circunstancias políticas de la época. 
La nueva simbología en Venezuela a través de actos de jura, festividades y música a principios del siglo XIX

Siguiendo a Nieto (1993) los símbolos y los signos plasman su valor en tanto que se les considera no solo como afirmación del poder, sino también como sustento de su legitimación y eficacia propagandística. En ese sentido, ceremonias, ritos, fiestas y canciones patrióticas entre otros contribuyen a instituir y a confirmar unas relaciones de poder, en las que gobernantes y gobernados pretenden simbolizar el nuevo escenario político.

De cualquier modo, los símbolos se hacen legitimadores ya que logran sustentarse a través de una realidad edificante que presenta las imágenes como verdaderas, una visión fehaciente de lo que se vive en la historia y que convenientemente pretende servir como fundamento de los ideales provenientes del ancienrégime ${ }^{1}$ que entrelazados con los principios liberales - republicanos comienzan a tomar gran relevancia en todas las provincias venezolanas a partir del siglo XIX.

De todos modos, a partir de la escenificación de signos y símbolos, el fin es de una parte, generar opinión y apoyo; de otra, legitimar el nuevo discurso que personifica la nación de corte liberal. Discurso que progresivamente se impone y sustituye el de la lealtad y de la fidelidad a la monarquía y al rey.

Efectivamente, este nuevo escenario requiere de otros actores y de otras significaciones, y para ello las ceremonias como actos confirmatorios y ratificadores, son fundamentales. En opinión de Leal (1990), ellas envuelven símbolos verbales y no verbales como, por ejemplo, inclinar la cabeza, la ubicación de alguna autoridad real sea en una ceremonia u otro acontecimiento, un gesto, un pendón, enarbolar una banderaasí, se les considera como instrumento esencial en la estabilidad del orden político.

En el caso que aquí nos ocupa, es evidente el derrotero que muestra la crisis de la monarquía española; y las propias dinámicas internas que definen ocupación y

\footnotetext{
${ }^{1}$ Antiguo Régimen (en francés: Ancienrégime) término empleado por los revolucionarios franceses que designaban a la forma de estado anterior a 1789, y que se aplicó también al resto de las monarquías europeas, cuyo régimen era similar.
} 
uso de los espacios dejan sentir sus consecuencias. De un lado, los defensores de la monarquía; de otro, los defensores de la república. Estas posturas se ponen en escena en los diversos espacios de acción y de opinión, y develan la presencia aunque muy tímida de nuevos imaginarios y de nuevos significados. En todo caso afirma Berbesí (2000b) si bien cada celebración, cada ceremonia y cada acto representaba y ratificaba los valores sociales de fidelidad y de lealtad de los vasallos a la monarquía, a la religión católica y a la patria; se advierten ya públicamente los deseos, las intenciones y la necesidad de significar los ideales de la libertad y de la independencia. En adelante, las luchas se van a desarrollar en estricta correspondencia con estos ideales.

En ese sentido, el trabajo que se presenta busca generar aportaciones sobre la nueva simbología "republicana" en las primeras décadas del siglo XIX.El objetivo es destacar los dispositivos discursivos que explican tal construcción a partir de algunas ceremonias, actos públicos, fiestas, canciones que ponen en escena símbolos y signos que aunque en el contexto de corte antiguo "legitimadores de la monarquía y sus prácticas," buscan durante toda la coyuntura independentista imponerse y hacerse necesarios con el propósito de asegurar los principios que consoliden efectivamente la estabilidad de la nueva repúblicaasimismo se estudiaran algunas canciones que fueron símbolos emblemáticos de la naciente república.

\section{Los Actos de Jura}

El acto de jura representa el símbolo ${ }^{2}$ de la conciliación y entrega de los súbditos con la monarquía, que implica fidelidad y obediencia. En este sentido se da por ejemplo, la jura de la constitución española de 1812, fervientemente proclamada

\footnotetext{
${ }^{2}$ Al respecto la Dra. García (1996) advierte que los símbolos son epifánicos, es decir, van más allá de lo que vemos, están presentes en los diferentes recursos que las sociedades utilizan en su organización, por lo que todas las actividades y prácticas culturales y religiosas están inmersas en los sistemas simbólicos. Son los dispositivos simbólicos los que permiten y reproducen la realidad, la interpretan e identifican y todo esto se logra a través de los símbolos.

61
} 
La nueva simbología en Venezuela a través de actos de jura, festividades y música a principios del siglo XIX

en buena parte de los territorios de la extinta capitanía general de Venezuela. El ceremonial con que se festejó devela una especie de pacto social que involucró a todos por igual, pues el objetivo era el bien común, muy bien explicitado en el texto constitucional gaditano de 1812 .

De ese modo, dicho texto es adoptado y apropiado por todos; pues en sí, simboliza el deseo de participación colectiva, de patria y de libertad. Para Reyero (2010), su jura se asume como un ritual con el que se quiere demostrar el triunfo de la libertad sobre el despotismo.

Legitimar e imponer los cambios consagrados en el texto constitucional, ahora, máxima expresión de libertad, de igualdad y de justicia rige el camino para su difusión y aceptación. Lo que se impone pese a todo, es la necesidad de legitimar y reafirmar una nueva identidad, y en ello, tal como lo ha señalado Reyero (2010), la constitución en sí misma representa un referente de identidad distinto al de súbdito.

La proclamación de la constitución en algunas localidades y regiones de la antigua capitanía general de Venezuela, se asumió como una festividad pública de carácter memorable y ratificador de unas nuevas pretensiones de poder. En Caracas por ejemplo, el 29 de noviembre de 1812, se juramentó el texto constitucional en la plaza mayor de la ciudad. Acto presidido según el ceremonial de la época por el gobernador y capitán general. Como máxima autoridad de gobierno, Domingo de Monteverde junto a su ejército asistió a la misa solemne cantada por Mons. Narciso Coll y Prat; seguidamente, salió en procesión junto a las demás autoridades y ciudadanos para que la población fuera partícipe del ceremonial, y a la vez, manifestaran fidelidad al nuevo símbolo que estaban presenciando: la constitución (Salvador, 2001).

La plaza mayor con el retrato de Fernando VII y un epígrafe que señalaba su esplendor, la fidelidad de sus vasallos y el amor que su pueblo le profesaba, se encontraba decorada con palmas y ramos para tan importante acontecimiento. El centro estaba cubierto con alfombras y damasco rojo, al frente y a los lados se 
hallaban inscripciones que exaltaban la majestuosidad y grandeza del régimen monárquico(Salvador, 2001).

Esta exaltación iconográfica de Fernando VII muestra el uso de un símbolo eminentemente político con el que se quiere imponer la institucionalidad monárquica al parecer de los liberales de turno, no irreconciliable con el mensaje constitucional. De lo que se trata, señala Reyero (2010), es de significar a Fernando VII como el promotor y responsable de sancionar y promulgar la nueva ley.

De igual manera para ratificar el poder monárquico, en las esquinas norte, sur y este de la plaza mayor se encontraba el batallón de voluntarios de Fernando VII uniformados y apertrechados, mientras que en la esquina oeste dos cañones que apuntaban hacia el escenario donde Monteverde clamó ante toda la multitud "soldados de las Españas: vais a oír la constitución política de la monarquía española, hecha por la felicidad común por las cortes generales y extraordinarias del reino. Atended" (Gaceta de Caracas, 1812: citado por Salvador, 2001).

Luego de ser leído el texto por horas, Monteverde procedió a jurarlo con la mano puesta sobre el devocionario y el crucifijo juró guardarle fidelidad y asumir el compromiso de hacer cumplir y dar a conocer lo planteado en la nueva carta magna. Como acto político de escenificación pública, su jura convoco a variados sectores sociales, pues la ocasión ameritaba la concordia, la armonía y la aceptación de todos. Seguidamente, al compás de música en honor a la constitución, a la madre patria y al monarca, hubo salvas de artillería y fusilería. En las casas consistoriales se ofreció banquetes y en la noche una iluminaria general por tan importante acontecimiento (Salvador, 2001).

Tras lo ocurrido en Caracas, las demás provincias pertenecientes a la antigua Capitanía General de Venezuela, buscaban de la misma manera demostrar al rey y la monarquía, su absoluta fidelidad y entrega a la nueva constitución monárquica de 1812. Para ello, recurren a la organización y realización del ceremonial y a las 
La nueva simbología en Venezuela a través de actos de jura, festividades y música a principios del siglo XIX

sucesivas fiestas, quepretendían exhibir la mayor ostentosidad, como símbolo del amor y veneración de los vasallos a su amado soberano.

Así, por orden del Gobernador político de la ciudad de Maracay y del Teniente de Justicia Mayor don Monseñor Martín Domínguez, el pueblo del Guapo, a partir del 23 de julio de 1812 celebra con un gran festejo la publicación y jura de la constitución política de la monarquía española, sancionada por las cortes generales y extraordinarias de la nación promulgada en Cádiz. Como acto político de significativa importancia, las autoridades del pueblo se organizaron para dar cumplimiento al ceremonial que merecía tan digno acontecimiento. ${ }^{3}$

De ese modo, se ordenó a los vecinos entapizar, limpiar y asear sus casas con la decencia que el caso merecía, sobre todo las ubicadas cerca del lugar en el que pasarían las autoridades- desde el tribunal hasta la esquina de Don Ysidro Colomedas, y desde allí hasta llegar a la iglesia(Archivo General de Indias, 1812a).

Los vecinos deberán iluminar sus casas por tres noches consecutivas, manifestando su entusiasmo, regocijo y respeto con la finalidad de que tan importante evento perviviera en la memoria del pueblo.

Asimismo, se envió un oficio al venerable cura párroco del pueblo Don Fernando Amezquita, para que en obsequio a tan sagrada función, solemnizará una misa cantada en acción de gracias al espíritu santo, acompañado de las personas

\footnotetext{
${ }^{3}$ El estudio de las fuentes primarias manuscritas se abordó desde el Archivo General de Indias esta investigación nace del proyecto titulado "Representación política, conflictos y opinión en la construcción de la república. Venezuela, 1808-1830", siendo responsable la Dra. Ligia Berbesi.Como parte del equipo de asistentes de investigación, desde el período de 2008 al 2012 surge la necesidad de comprender desde el estudio de lo histórico y antropológico los referentes simbólicos que legitiman la monarquía en sus posesiones americanas y cómo los símbolos intervienen y se consolidan tras la ruptura del orden establecido y nacimiento de la nación Venezolana. No se contó con el Registro Principal del estado Zulia buena parte del periodo en estudio no hubo acceso a la sala de documentos para los investigadores por reestructuración de sus instalaciones.
} 
blancas más respetables y demás autoridades de la jurisdicción (Archivo General de Indias, 1812a).

Igualmente, se celebró el ceremonial al son de la música, caja militar y salvas que incluían discursos y cámaras que mostraban la grandeza que representaba la constitución como símbolo legitimador de la monarquía. Precisamente, la finalización del ceremonial devela la importancia concedida a este acto. Como muestra de concordia y de voluntad colectiva- autoridades civiles, eclesiásticas y el pueblo-, todos congregados en la iglesia parroquial se confunden para solemnizar armoniosamente y dar testimonio de reafirmación y reconocimiento de su libertad.

De igual forma, en el Puerto de la Guaira no se pasaría por alto dicho acontecimiento. Desde el 4 de junio hasta finales de mes el presidente de la municipalidad Don José Catusla junto a las demás autoridades, acuerdan prestar juramento a la carta constitucional. Diputados, ministros de hacienda pública, el contador y sargento mayor de la plaza, comandantes de artillería y el administrador de la renta nacional de correos reunidos y por mandato del referido presidente, inician los actos oficiales. A tal efecto, Don José Catusla dispuso en las manos del sargento mayor de la plaza en la forma siguiente:

"Jurando de pie derecho, y con las manos puestas sobre el libro, abierto, de los Santos evangelios i guardar y hacer guardar la constitución política de la monarquía española... y ser fiel al Rey a lo que contestó: Si Juro. Y seguidamente el Ciudadano Presidente recibió igual juramento de la Diputación en Cuerpo, y en particular a cada uno de los Ciudadanos jefes de corporación..." (Archivo General de Indias, 1820Caracas 178, Tira 27. a).

Concluida esta ceremonia el ciudadano presidente y demás autoridades se dirigen al lugar destinado para la publicación de la constitución. Es de suponer que dada la importancia de dicho acto, se presume su realización en un espacio público como una plaza o calle principal. Desde allí, el magistrado Don José Catusla en esta ocasión y en medio de las salvas de artillería, dio inicio con su juramento al acto. Luego en compañía de los vecinos se dirigió al magnífico tablado decorado con 
La nueva simbología en Venezuela a través de actos de jura, festividades y música a principios del siglo XIX

diversas inscripciones, emblemas y alegorías que incluían al sagrado código llevado en un almohadón regado de flores, junto a cuatro (4) niñas vestidas de ninfas ${ }^{4}$ dentro de un carro tirado por los principales ciudadanos de la localidad. Mostrando en todo momento entusiasmo, alegría, respeto, exaltación y vivas a la constitución, a la nación y al rey.

Al llegar al recinto de la augusta ceremonia las ninfas se dispusieron a subir al magnífico tablado junto a las autoridades presentes, quienes se colocaron en sus respectivos asientos, bajo un templete magnifico que en sus cuatro arcos sostenían inscripciones, emblemas y alegorías alusivas a la ocasión. El presidente procedió a tomar la constitución del almohadón e inclinándose dio principio a su lectura alternando enseguida con los demás municipales (Archivo General de Indias, 1820a).

Los visitantes guardaban silencio en señal de obediencia y veneración mientras escuchaban de las autoridades el sagrado y sabio contenido. Concluido este acto se colocó la constitución en el carro para recorrer las principales calles del pueblo y leer en varios parajes artículos de la carta magna, siempre entre vivas y libre exaltación de todos los presentes, que no dudaron ni un instante en cargar sobre sus hombros por varias ocasiones el carro, no encontrando sus corazones mejor muestra de la total fidelidad y amor a los símbolos que representaban el poder y legitimidad de la monarquía.

La forma en que es movilizada la carta magna- puesta sobre un almohadón regado de flores junto a cuatro (4) niñas vestidas de ninfas, dentro de un carro que era llevado en hombros por los vecinos de la localidad-, hace una alusión casi perfecta de algunos ceremoniales de corte religioso en el traslado de vírgenes, santos y deidades con lo cual no solamente se aseguraba la unión y legitimidad religiosa de dicha

\footnotetext{
${ }^{4}$ Las ninfas son deidades griegas que suelen ser utilizadas para representar atributos como la justicia, la libertad, el conocimiento, la patria.
} 
constitución sino que además se reafirmaba la grandeza e importancia de la mencionada carta magna.

En cuanto, a la denominación utilizada para referirse a la constitución una vez más, se observa la utilización de la religión para legitimar el simbolismo constitucional. Es decir, se acepta o al menos para muchas culturas es así, que los libros religiosos más importantes como la Biblia, el Talmud, los libros Veda, el Corán son considerados sagrados; es por ello que al afirmar que la constitución monárquica era un sagrado código, simbólicamente se iguala con estos textos y por consiguiente se le confiere una legitimidad casi absoluta y divina, es decir, que la constitución es el más significativo símbolo de la religión civil del Estado.

La iglesia como símbolo visible e ineludible del poder que caracteriza a la sociedad de antiguo régimen ${ }^{5}$, se hace presente en estos actos. Su presencia busca no solo invocar la bendición divina para resguardar el orden político ya restituido, sino también su legitimación. En consecuencia, el templo como espacio referencial es adornado e iluminado con el mayor gusto posible por su venerable Cura Párroco José Vicente Vergara, que inflamado con un gran entusiasmo ofreció un solemne Te Deum $^{6}$ en acción de gracias a la constitución y a la santa religión. Evidentemente, la alegoría religiosa acompaña al orden político que se pretende renovar al amparo constitucional de 1812.

\footnotetext{
${ }^{5}$ Por antiguo régimen se asume el periodo histórico que vivió Europa entre 1500 y 1789, en la que valores sociales, códigos simbólicos y relaciones de poder caracterizan una sociedad jerarquizada y estamental. Según Norbert (1982), esta sociedad buscará en todo momento la preservación y conservación del orden político y la subordinación social, de ahí que la actuación del colectivo girará de acuerdo a su status y posición. Es decir, que como sociedad estamental encontramos como guía y protector del reino al rey quién es el que asegura la calma, paz y estabilidad en todos sus territorios.

${ }^{6}$ Te Deum (latín: 'A ti, Dios', primeras palabras del cántico) es uno de los primeros himnos cristianos, tradicional de acción de gracias, utilizado comúnmente dentro de la iglesia católica.
}

67 
La nueva simbología en Venezuela a través de actos de jura, festividades y música a principios del siglo XIX

Igualmente, el ceremonial establece el camino a seguir para visibilizar y personificar la debida atención a los valores constitucionales que darán continuidad a la nación española. Luego de la alegoría religiosa, entre las salvas de artillería y otras demostraciones de júbilo, las autoridades y demás ciudadanos se encaminaron a la casa del gobernador entonando vivas y aclamaciones, que incluían al presidente y la distinguida diputación. A su vez, durante los ocho (08) días feriados decretados por la municipalidad para la celebración, se ordenó la realización de bailes y comedias para el disfrute de todo el pueblo, por lo que el tablado estuvo habilitado hasta las once (11) de la noche para que disfrutaran hasta la hora pautada con el mayor orden, decoro y sinceras vivas y jubilo extraordinario. Asimismo, se ordenó la iluminación general y la decoración de los frontis de las casas con varios emblemas y poemas que exaltaban la paz y la unión fraternal.

Evidentemente, la calidad del ceremonial y festividades en la Guaira hablaba del deseo de sus vecinos por mostrar la adhesión al pacto social que tenían con la monarquía. Además, se logró demostrar la prosperidad económica del puerto a pesar de todas las convulsiones políticas en las que estaba inmersa Venezuela.

Otro acto de jura a la constitución política de la monarquía fue el ocurrido en la provincia de Coro para julio de 1820. Su majestuosidad y esplendor develan su importancia. La significación alegórica al mismo, así como la pompa y fastuosidad con las que dicha población celebró, evidencian las pretensiones de poder y, como tal, la intencionalidad política de quienes lo controlan y lo dirigen.

..." Vista la orden del Excelentisimo Señor General en Jefe y Comisionado Regio Don Pablo Morillo que se recibio a las nueve de la noche del dia de ayer con repiques de todas las campanas y con el mayor aplauso y gusto de guantos entendieron; cumplan, guardese y executese como en ella se previene a ese fin anunciere al publico por bando con la mayor solemnidad tan laudable providencia y que se publicará y jurará la Constitución política de la Monarquia Española el dia veintinueve de los corrientes a las cuatro de la tarde, que és el qué su Señoria Acordó con los Señores Alcaldes Ordinarios, Don Mariano 
Arcaya y Don Antonio Navarrete..." (Archivo General de Indias, 1820Caracas 177, Tira 79. b).

Así, con el decoro y solemnidad del caso, las autoridades de esta comunidad hicieron participe a todos los pobladores de su jurisdicción de tan significativo acontecimiento. Por ello, se ordenó a todos los vecinos a que adornasen sus casas con toda la magnificencia posible, limpiando y aseando las calles sobre todo las ubicadas por el lugar que iba a pasar la carreta. Asimismo, esa noche y las siguientes se iluminase toda la ciudad no dejando de manifestar su entusiasmo y regocijo en señal del amor a nuestro amado rey representado en los símbolos que se hacían visibles.

En ese sentido, luego de fijar los carteles en los lugares públicos y acostumbrados se procedió el día veintinueve (29) a las cuatro (4) de la tarde en la sala capitular con el respaldo del señor gobernador político militar e intendente de esta provincia coronel de los ejércitos nacionales Don Miguel Correa y demás autoridades se dirigieron a la plaza de la parroquia donde se encontraban las tropas de artillería e infantería con la gran concurrencia de vecinos de diferentes clases, y subiendo al tablado diseñado para la ocasión se dio inicio a la lectura de la constitución. Una vez, finalizada la misma, el señor alcalde Don Mariano Arcaya tomó juramento al señor gobernador que hizo por Dios y por los Santos Evangelios de guardar y hacer guardar la constitución política de la monarquía y ser fiel al rey, por lo que enseguida el señor gobernador recibió juramento de las demás autoridades presentes (Archivo General de Indias, 1820b).

Seguidamente, se realizaron salvas de artillería e infantería acompañadas de "vivas a la nación, al rey y la constitución," dirigiéndose al mismo tiempo los citados señores a la sala capitular acompañados por las tropas y vecinos que aclamaban constantemente a la nación, al rey y la constitución.

\footnotetext{
${ }^{7}$ El documento se transcribe tal cual al original de la época, por ello su ortografía no es la correcta para la actualidad. Pero el historiador no debe alterar el documento. 69
} 
La nueva simbología en Venezuela a través de actos de jura, festividades y música a principios del siglo XIX

Posteriormente, se celebró misa y se cantó un solemne te deum en honor a la constitución, desde ahí el señor gobernador tomó el juramento del pueblo y el clero presente concluyendo el acto con salvas de artillería.

De igual manera, el pueblo de Maracaibo para 1812 da muestras de la lealtad a la monarquía y expresa que el llamado de Caracas a constituirse independiente del gobierno de España, solo produjo un efecto contrario a lo esperado por la junta central, es decir, "la fiel y leal Maracaibo, se mantendrá obediente a su monarquía y a su rey." En consecuencia, como clara manifestación no solo del control político que se tiene de la ciudad, sino también de la necesidad de advertir a todos y a todas de la defensa de los intereses reales, mediante dispositivos de carácter eminentemente simbólicos, interpretados y aceptados por la mayoría de la sociedad; se ordena una vez jurada la constitución que en acto público se quemen los papeles subversivos e irreligiosos, ${ }^{8}$ al igual que las banderas alusivas a la independencia (Archivo General de Indias, 1812b). Con la plaza mayor como escenario, se pretende demostrar la total desaprobación a los símbolos sediciosos, y en consecuencia, la sucesiva fidelidad del pueblo a la causa del rey.

Con la quema en la plaza pública de estos referentes simbólicos- propaganda sediciosa y banderas-, que representan la causa patriótica la cual progresivamente comienza a revolucionar a las provincias venezolanas, se pretende de una parte, ratificar la necesidad de todos por significar y valorar su lealtad a la monarquía; asegurando así a la madre patria la subordinación de sus súbditos. De otra, advertir de la exaltación y la consolidación ante todo el colectivo, de la constitución política gaditana de 1812 confirmada por las cortes extraordinarias de la nación.

En consecuencia, durante todo el proceso emancipador la corona intentará en todo momento, y más en tiempos de crisis reforzar todo el andamiaje simbólico que permitirá significativamente afianzar el poder regio existente.

\footnotetext{
${ }^{8}$ El documento no hace alusión al contenido de los papeles.
} 
Queda demostrado que los actos ceremoniales ponen en escena un sin número de códigos simbólicos, que materializan y sacralizan el poder reinante. Esto es, un acto público se transforma simbólicamente en un hecho muy importante con la sola inclusión de un retrato del rey Fernando VII, esto porque al incluir tal símbolo en el ceremonial, se traslada toda la autoridad y el poder del monarca a dicha celebración, lo que representa que lo invisible se haga visible y lo común se vuelva sagrado e importante, asimismo, la jura permite afianzar el pacto de fidelidad entre los gobernantes y gobernados. En opinión de Chartier (1992), signos y símbolos van más allá al manifestar las pretensiones de los que controlan y ejercen el poder, es decir, se determinan posiciones, relaciones y estatus en cada grupo o clase social a la que se pertenece.

En ese sentido, es trascendental señalar el significado y funciones de las celebraciones pues al igual que en el pasado reciente, engloban un sistema de deberes, compensaciones o retribuciones que hacen posible su existencia y contribuyen a su conservación. De ahí la importancia de la jura como ente que legitima y consolida públicamente la superioridad de la institucionalidad monárquica y lo que ello implicaBerbesí (2000 a).

\section{Festividades y Diversiones}

En la Venezuela del siglo XIX el poder que se impone según Salvador (2001), utilizará las fiestas cívicas, ${ }^{9}$ como instrumento político de autopropaganda y control sobre la sociedad con la finalidad de asegurar la fidelidad y lealtad de los súbditos, el resguardo a las instituciones políticas, la aglutinación y aceptación del orden existente.

En consecuencia, a lo largo del siglo XIX las fiestas se hicieron más notorias sobre todo en los tiempos de crisis cuando se buscaba exaltar y conmemorar con gran

${ }^{9}$ Son las solemnidades públicas de índole patriota. 
La nueva simbología en Venezuela a través de actos de jura, festividades y música a principios del siglo XIX

júbilo las entradas triunfales de los realistas o patriotas según fuese la situación política en la que se encontraban las provincias de Venezuela. Asimismo, se conmemoraran las fechas que estaban cargadas de un alto contenido simbólico para la naciente república, tales como el diecinueve (19) de abril de 1810 y el cinco (5) de julio de 1811.

Interesa destacar el regocijo que el pueblo de Caracas manifestó tras la llegada de José Tomás Boves el día 16 de julio de 1814. Sus tropas fueron recibidas con el mayor júbilo y muestras de total fidelidad del colectivo a la causa del rey (Archivo General de Indias, 1814).

Para tan importante acontecimiento el propio monseñor Narciso Coll y Pratt espera a Boves $^{10}$ tras su llegada a Caracas, deseoso de brindarle un caluroso recibimiento, hasta tal punto de ofrecerle la sede arzobispal para su hospedaje e incluso llegar a decir, "que después de Dios era a este jefe militar a quien le debía la vida."

“...En esta recepción - apunta un testigo- "venía un gran concurso de pueblo, y hubo música, fuegos artificiales y se echaron a vuelo las campanas." Serían en total unas cinco mil almas las que estarían aguardando a Boves..." (Mondolfi, 2005, p. 107).

Asimismo, los acontecimientos de la gesta independentista serán tomados como días de fiesta nacional ya que constituirán fechas esenciales que ratificaran e irán forjando los valores republicanos, como por ejemplo el 19 de abril de 1810 y el 5 de julio de 1811. Con estas celebraciones a lo largo del siglo XIX las autoridades republicanas encabezadas por los presidentes de turno se desvivirán por el logro, mayor majestuosidad y trascendencia de estas solemnidades patrias, lo que nos lleva a

${ }^{10}$ José Tomás Boves: Conocido como el león de los llanos, caudillo y militar español que intento unirse a la causa independentista, pero por el desprecio de las élites criollasterminó apoyando la causa del rey, con su discurso popular de igualdad social para los pardos y negros logró unir un ejército que fue decisivo en la caída de la segunda república venezolana 1813. 
comprender que cada una de las actividades desarrolladas forman parte de ese capital simbólico, que pretendía exaltar a la patria y sus líderes con la finalidad de darle cohesión y significado a la nación que se intentaba construir.

Ejemplo de lo anterior es que en toda Venezuela se celebra el 5 de julio, fecha que se conmemora la declaración definitiva de nuestra independencia. La misma fue proclamada con gran júbilo en Caracas el 14 de julio de 1811 por orden de Francisco de Miranda. Para dichas festividades se realizaron redobles de campanas, misa con te deum, se enarboló la bandera republicana en los edificios públicos y en la plaza mayor entre salvas de artillería la capital permaneció iluminada por tres noches consecutivas Salvador (2001).Se distribuyeron por toda la ciudad, notas con versos en las que invitaban al pueblo a decorar e iluminar las fachadas de sus hogares. También se realizaron diversos espectáculos que incluían prácticas de corte antiguo, con la inserción de nuevos elementos que tienen la finalidad de exaltar la grandeza de la patria libre e independiente del yugo monárquico.

De allí que la fiesta representa por una parte, la necesidad del espíritu humano de vivir y de compensar de alguna u otra manera las adversidades y situaciones que se experimentan a diario. Por otra, desde lo político significa y ratifica una forma de hacer política que privilegia la sociedad heredera del orden tradicional que no dejo de ser la excepción, por lo que se recurría a las festividades como un escape ante tanta rigidez que significaba el pertenecer a un mundo jerarquizado con tantos códigos de comportamiento y estatus que lo definía. ${ }^{11}$

En ese sentido, de un bando u otro las fiestas buscaban en todo momento exaltar la importancia de los valores provenientes de la ortodoxia católica, la jerarquización social y el reconocimiento de la tradición como elementos legitimadores de la sociedad.

${ }^{11}$ Véase Ramos (1997). "La fiesta barroca en ciudad de M éxico y Lima," enHistoria. vol. 30, Chile. pp. 263-286. 
La nueva simbología en Venezuela a través de actos de jura, festividades y música a principios del siglo XIX

\section{La Música como Símbolo de Identidad Nacional.}

La guerra de independencia sin proponérselo quizás alentó valores y sentimientos encontrados - identidad, justicia, patriotismo, libertad, igualdad entre otros-, significados ahora en el discurso de la "felicidad pública", con el que se pretende unir a todos, encontró en la música una forma más de apuntalar el ideal republicano. En otras palabras, con la música como símbolo legitimador y cohesionador, se pretendió formar a los republicanos que se requerían para alcanzar la consolidación de la república. De ahí el empeño de las voces de la emancipación en su difusión.

$\mathrm{Al}$ estudiar la trascendencia de la música como símbolo cohesionador de la sociedad utilizado por el bando republicano para justificar su proyecto de independencia Ernesto Mora, Jean González y otros, señalan que

"Las luchas armadas entre los americanos y españoles por el control del territorio se consustanció con la competencia por el control de un conjunto de elementos culturales en los cuales las personas se veían representadas. De esta manera, los grupos en pugna esperaban que el control de los elementos culturales e identitarios de la población garantizara la adhesión a sus respectivas causas. Entre este conjunto de elementos culturales utilizados por los republicanos para cohesionar a la sociedad en torno a las representaciones colectivas de la nueva nación, la música jugó un papel estelar" (Mora et al,2010, p.296).

En ese sentido, las loas en coplas y demás musicales de índole popular constituyen elementos culturales que definen la identidad de la sociedad venezolana, que se transforma a raíz de todo el proceso emancipador y conduce a una nueva organización socio-política, donde la música juega un papel central en la lucha por la redefinición como uno de los símbolos emblemáticos y sobre todo representativos del ideal republicano.

En medio de tantas disputas, cada cántico era ofrecido en honor a la nueva nación y a los héroes que han hecho posible el surgimiento de la patria venezolana. El gloria al bravo pueblo de Andrés Bello y Lino Gallardo; La canción americana de J. Picornell y Lino Gallardo; A Bolívar canción patriótica de Lino Gallardo; para los 
libertadores del sur de José María Isaza; Visita del libertador, de Juan Meserón y la Canción patriótica en obsequio al Libertador 1825, entre otras, constituyen ejemplos al respecto. ${ }^{12}$

Por ello, se recurre al análisis del discurso como herramienta metodológica, y en el caso que aquí nos ocupa en acuerdo con Molero de Cabezas (2003), podemos afirmar que el discurso en cualquiera de sus manifestaciones es siempre de carácter referencial y cognitivo y además, conceptualiza una realidad que también es contextual e intencional.

En esta consideración, el estudio y comprensión de algunas canciones patrióticas de la época evidencia que estas siempre tuvieron un propósito específico y aluden una determinada realidad.

Como evidencia de lo anteriormente señalado se presentan algunas canciones de índole revolucionario (véase cuadro 1) que surgidas durante el proceso de independencia develan la intencionalidad de significar en los distintos colectivos no solo la visión republicana que se requería para la unificación de la patria, sino que también era necesario encarnar a su vez la tiranía y la opresión, de la monarquía como sistema de gobierno.

Para el caso de la canción patriótica se observa una exaltación de los ideales republicanos, del pueblo como soberano y lógicamente es ahí donde recae la legitimidad. Igualmente, se hace alusión a la madre patria que ya no será entendida como la patria española, sino como el lugar donde se nace, la patria Venezuela. De esta manera, se percibe la unión de símbolos religiosos sagrados con los valores

${ }^{12}$ Las canciones de índole patriótico fueron facilitadas en su momento por la http://laestancia.pdvsa.com más en la actualidad la página no muestra las coplas de la gesta independentista, para indagar más detalladamente las canciones que fueron un símbolo emblemático de la causa independentista durante el siglo XIX. Revisar Castro (2012). La Simbología del poder en la construcción de la república. Venezuela, 1808 -1830.Trabajo de Grado para optar al título de M agíster Scientiarum en Historia de Venezuela. Universidad del Zulia. Venezuela 
La nueva simbología en Venezuela a través de actos de jura, festividades y música a principios del siglo XIX

republicanos, ya que al afirmar primero, que el pueblo recobra sus derechos sagrados y segundo, que el ser infinito y divino había dotado al hombre de libertad, básicamente se estaba planteando la idea que el pueblo al abrazar los ideales republicanos estaba retornando la sagrada libertad que le había sido otorgada por Dios, y que los españoles en su cruel despotismo le habían arrebatado.

La visión monárquica de la canción nos presenta un enfoque sumamente negativo del bando español, al ser calificado este grupo de opresores, tiranos, infames, inhumanos, sanguinarios y monstruos que mantenían esclavizada y afligida a nuestra patria y por tal razón debían morir.

Por otra parte, en los canticos la figura de Simón Bolívar y de quienes lo acompañaron en la gesta independentista, simbólicamente fueron presentados de manera mítica y gloriosa, esto con la intención republicana de ir transformando y cambiando los referentes simbólicos- alabanzas-, que se observaban en las canciones, es decir, tal como lo hacían en los actos de jura la idea era modificar la imagen divinizada del rey, por el de un nuevo líder que guiara a nuestra patria y especialmente uno que como Bolívar representaba todos los ideales de hombre ilustrado que la nueva patria requería.

Cuadro 1.

Canciones de índole revolucionario, surgidas durante el proceso independentista.

\begin{tabular}{|c|c|c|}
\hline Canciones & Visión republicana & Visión monárquica. \\
\hline $\begin{array}{c}\text { Canción Americana } \\
\text { (1811). } \\
\text { Lino Gallardo } \\
\text { J. Picornell } \\
\text { C. Campomanes. }\end{array}$ & $\begin{array}{l}\text { Viva el Pueblo } \\
\text { Pueblo soberano } \\
\text { Patria: nuestra madre } \\
\text { querida } \\
\text { El pueblo recobró sus } \\
\text { derechos sagrados } \\
\text { Ser infinito supremo y } \\
\text { sabio que creó al hombre } \\
\text { de libertad dotado. }\end{array}$ & $\begin{array}{l}\text { Mueran los opresores } \\
\text { Tirano (tuvo a la patria } \\
\text { esclava y afligida) } \\
\text { Opresor, inhumano, } \\
\text { infame, déspota y } \\
\text { sanguinario } \\
\text { Monstruos feos y } \\
\text { horrendos; destruye a los } \\
\text { americanos, crímenes }\end{array}$ \\
\hline
\end{tabular}




\begin{tabular}{|c|c|c|}
\hline & & salvajes \\
\hline $\begin{array}{l}\text { Canción Patriótica } \\
\text { para la Visita del } \\
\text { Libertador (1827). } \\
\text { Juan Meserón. }\end{array}$ & $\begin{array}{l}\text { Bolívar su gloria inmortal } \\
\text { Nuestra patria afligida. } \\
\text { Bolívar de tierras lejana } \\
\text { lamentos y quejas oyó. } \\
\text { Vuela cual rayo } \\
\text { impetuoso. } \\
\text { Una rama de olivo } \\
\text { mostró. }\end{array}$ & $\begin{array}{l}\text { Desgracias que un mal le } \\
\text { causó. }\end{array}$ \\
\hline $\begin{array}{l}\text { Gloria al Bravo } \\
\text { Pueblo (1810). } \\
\text { Andrés Bello } \\
\text { Lino Gallardo. }\end{array}$ & $\begin{array}{l}\text { Gritemos con brío. } \\
\text { Compatriotas fieles la } \\
\text { fuerza es la unión. } \\
\text { El supremo autor, un } \\
\text { sublime aliento al pueblo } \\
\text { infundió. }\end{array}$ & $\begin{array}{l}\text { Muera la opresión. } \\
\text { Que el yugo lanzo. } \\
\text { Abajo cadenas. } \\
\text { Y si el despotismo levanta } \\
\text { la voz. }\end{array}$ \\
\hline $\begin{array}{l}\text { Para los Libertadores } \\
\text { del Sur (1825). } \\
\text { José María Isaza. }\end{array}$ & $\begin{array}{l}\text { Gloria a los bravos } \\
\text { guerreros. } \\
\text { Nos dan libertad. } \\
\text { Gloria al genio creador... } \\
\text { que ha luchado hasta } \\
\text { darnos la paz. } \\
\text { Héroes guerreros, genio } \\
\text { inmortal. } \\
\text { Mano divina que a } \\
\text { Colombia le ha dado la } \\
\text { paz. }\end{array}$ & \\
\hline $\begin{array}{l}\text { Canción Patriótica en } \\
\text { Obsequio al } \\
\text { Libertador (1825). } \\
\text { José María Isaza. }\end{array}$ & $\begin{array}{l}\text { Caraqueños tributan } \\
\text { afecto y lealtad. } \\
\text { A Colombia le dio } \\
\text { libertad. } \\
\text { Reina ya la libertad. }\end{array}$ & $\begin{array}{l}\text { Soberbios y tiranos, Guerra } \\
\text { que nos ha destruido. } \\
\text { Nunca podréis ya triunfar. } \\
\text { Malvados. }\end{array}$ \\
\hline
\end{tabular}

Fuente: Elaboración propia. 
La nueva simbología en Venezuela a través de actos de jura, festividades y música a principios del siglo XIX

Como resultado, muchas de las canciones surgidas durante todo el proceso emancipador venezolano fueron consideradas subversivas y en consecuencia, fueron prohibidas por las autoridades monárquicas, esto se debe a que la música durante el ancienrégime fue utilizada con fines recreativos o ceremoniales en honor al rey, la corte y la religión; pero con el polvorín de la guerra la polarización y radicalización que viene acompañado con esta, van a influir en todas las expresiones de la sociedad y

en este caso, las canciones no serán la excepción, toman un cariz político y revolucionario en defensa de la república y de todos los valores que la representaban igualdad, libertad, fraternidad y justicia social.

De lo señalado, podemos afirmar que la música permitió diferenciar en todo momento la oposición existente entre españoles y americanos. Asimismo,en los cánticos estaban presentes ideas y creencias que exaltaban a los líderes durante todo el proceso emancipador. Mora et al (2010) ejemplo claro lo vemos en la figura guerrera, salvadora y divinizada de Bolívar que con su marcha veloz salva de los tiranos a su pueblo llevándoles paz y libertad.

Como es de suponer durante buena parte del siglo XIX, la música de índole patriótica será objeto de discriminación y prohibición. Evidentemente que la misma generaba adhesión por parte de la sociedad. De ahí la trascendencia de las canciones dentro de cada ceremonia, festividades y actos públicos como parte de todo el capital simbólico que legitimaría paulatinamente la nueva identidad nacional.

\section{Consideraciones finales}

En esta perspectiva, los resultados aquí expuestos procuran comprender otra variable de nuestro proceso independentista, esto es, la simbología del poder construida por individuos y colectivos sociales bien para reafirmar la estructura 
monárquica de poder, bien para legitimar el ideal republicano/liberal que se pretende imponer $^{13}$

En esta consideración, el objetivopropuesto de la investigación han develado que la sociedad de orden tradicional caracterizada por valores como el honor, la lealtad, la fidelidad, la obediencia, la sumisión y la subordinación, y una profunda valoración de lo sagrado y religioso, se manifiesta, pervive y coexiste con nuevos valores, conceptos y referentes - libertad, igualdad, fraternidad y unión -, devenidos de la crisis de la institucionalidad monárquica de fines del siglo XVIII y primeras décadas del siglo XIX.

El análisis ha evidenciado que esta simbología se significa en el discurso de la época mediante símbolos, valores, ceremonias, rituales, fiestas, entre otros donde prevalecen códigos que definen la posición y el lugar que cada individuo ocupa dentro de la sociedad, y a su vez, logra establecer los límites y alcances del ejercicio y funcionamiento del poder.

En ese sentido, cada manifestación alegórica, perseguía de una parte, generar apoyo, es decir, vasallaje, sumisión y obediencia al rey, de otra, legitimar el nuevo discurso que personifica la Nación de corte liberal. Discurso que progresivamente se impone y sustituye el de la lealtad y fidelidad a la monarquía y al rey.

En el contexto del nuevo orden político venezolano que comienza a configurarse en 1811, símbolos, valores, actitudes, prácticas y comportamientos apuntalan la construcción de la naciente República, que en adelante requiere legitimar una nueva simbología institucional y política. De ahí que la coyuntura histórica exige e impone cambios: soberanía, representación, participación política, opinión se construyen ahora desde nuevos y viejos significados, referentes y dispositivos

\footnotetext{
${ }^{13}$ Véase Castro (2014). "Reflexiones Teóricas del Antiguo Régimen: Poder y Simbología,"en Perspectivas, vol. 4, no 2, Venezuela. pp. 13-34. 
La nueva simbología en Venezuela a través de actos de jura, festividades y música a principios del siglo XIX

simbólicos que progresivamente trastocan actitudes, prácticas, comportamientos y valores.

\section{Referencias bibliográficas}

Archivo General de Indias. 1812a. Caracas 178, Tira 27. Testimonio del Pueblo de Guapo para Celebrar la Jura de la Constitución 24 de Julio.

Archivo General de Indias. 1812b. Caracas 177, Tira 79. Los Habitantes de Maracaibo Acreditan Jubilo a la Constitución de la Monarquía. Octubre.

Archivo General de Indias. 1814. Caracas 62, Tira 274. El Ayuntamiento de Caracas y a Nombre de los Habitantes de la Provincia. 19 de Septiembre.

Archivo General de Indias. 1820a. Caracas 178, Tira 22. Juramento a la Monarquía Española del Puerto de la Guaira. 4 de Junio.

Archivo General de Indias. 1820b. Caracas 178, Tira 23. Juramento a la Constitución Española en Coro. № 3.20 de Julio.

Berbesí de Salazar, Ligia.(2000a).El Gobierno Provincial de Maracaibo en la Gestación de la Primera República 1799-1810, editorial Sinamaica. Venezuela.

Berbesí de Salazar, Ligía.(2000b). Ceremonial y Poder en el Gobierno Provincial de Maracaibo a Finales del Gobierno Borbónico. En Martínez Ruiz Enrique /recopilado.Poder y Mentalidad en España e Iberoamérica. Ediciones Puertollano S.L. España.

Chartier, Roger. (1992).EI Mundo como Representación. Estudios sobre Historia Cultural, editorial Gedisa. España.

García Gavidia, Nelly.(1996). Consideraciones Generales sobre los códigos utilizados en la Invención, Re-creación y Negociación de la Identidad

Nacional.Opción. $\mathrm{N}^{\circ} .20$, Venezuela. pp. 5-38.

Castro Pirela, María de los Angeles. (2012). La Simbología del poder en la construcción de la república. Venezuela, 1808 -1830.Trabajo de Grado para optar al título de Magíster Scientiarum en Historia de Venezuela. Universidad del Zulia. Venezuela.

Castro Pirela, María de los Angeles. (2014).Reflexiones Teóricas del Antiguo Régimen: Poder y Simbología. Perspectivas, vol 4, nº 2, Venezuela. 13-34.

Leal, Carole.(1990).El Discurso de la Fidelidad. Construcción Social del Espacio como Símbolo del Poder Regio (Venezuela, siglo XVIII).Biblioteca de la 
Academia Nacional de la Historia. Fuentes para la Historia Colonial de Venezuela. Venezuela.

Molero de Cabeza, Lourdes. (2003). En enfoque semántico -Pragmático en el análisis del discurso. Visión teórica actual. Lingua Americana, año VII, $\mathrm{n}^{\mathbf{0}} 12$, Venezuela. 5-28.

Mondolfi, Edgardo.(2005).José Tomás Boves,Editora el Nacional. Venezuela.

Mora, Ernesto. González, Jean. Richard, Dianora. Ferreira, Ivette.(2010). Músicas y Mitos en la Construcción de la Nación Venezolana. EnBerbesí Ligia, Vázquez Belín / Compiladores. Vínculos y Sociabilidades en España e Iberoamérica Siglo XVI- XX, Editorial de la Universidad del Zulia (EDILUZ). Venezuela.

Nieto Soria, José Manuel. (1993). Ceremonias de la Realeza. Propaganda y Legitimación en la Castilla Trastámara,editorial Nerea. España.

Norbeth, Elías.(1982). La Sociedad Cortesana, Fondo de Cultura Económica. México.

Ramos Sosa, Rafael.(1997). La Fiesta Barroca en ciudad de México y Lima.Revista Historia, vol. 30, Chile. pp. 263-286.

Reyero, Carlos.(2010).Alegoría, Nación y Libertad. El Olimpo Constitucional de 1812,Editorial Siglo XXI de España editores S.A. España.

Salvador, José María.(2001).Efímeras Efemérides. Fiestas Cívicas y Arte Efímero en la Venezuela de los siglos XVII - XIX, 1era Edición, Universidad Católica Andrés Bello. Venezuela. 